\title{
Sacral Bone
}

National Cancer Institute

\section{Source}

National Cancer Institute. Sacral Bone. NCI Thesaurus. Code C33504.

One of the five bones of the spine that fuse to create the sacrum. 